\title{
A Transbasin Mode of Interannual Variability of the Central American Gap Winds: Seasonality and Large-Scale Forcing $\mathscr{O}$
}

\author{
JUN-CHAO YANG AND XIAOPEI LIN
}

Physical Oceanography Laboratory/Cooperation and Innovation Center for Marine Science and Technology, Ocean University of China and Qingdao National Laboratory for Marine Science and Technology, Qingdao, China

\section{SHANG-PING XIE}

Scripps Institution of Oceanography, University of California, San Diego, La Jolla, California, and Physical Oceanography Laboratory/Cooperation and Innovation Center for Marine Science and Technology, Ocean University of China and Qingdao National Laboratory for Marine Science and Technology, Qingdao, China

(Manuscript received 12 January 2017, in final form 10 July 2017)

\begin{abstract}
A transbasin mode (TBM) is identified as the leading mode of interannual surface wind variability over the Intra-Americas Seas across Central America based on empirical orthogonal function analysis. The TBM is associated with variability in Central American gap winds, most closely with the Papagayo jet but with considerable signals over the Gulfs of Tehuantepec and Panama. Although El Niño-Southern Oscillation (ENSO) is the main large-scale forcing, the TBM features a distinct seasonality due to sea level pressure (SLP) adjustments across the Pacific and Atlantic. During July-September, ENSO causes meridional SLP gradient anomalies across Central America, intensifying anomalous geostrophic winds funneling through Papagayo to form the TBM. During wintertime, ENSO peaks but imparts little anomalous SLP gradient across Central America with a weak projection on the TBM because of the competing effects of the PacificNorth American teleconnection and tropospheric Kelvin waves. Besides ENSO, tropical Atlantic sea surface temperature anomalies make a weak contribution to the TBM in boreal summer by strengthening the crossbasin gradient. ENSO and the Atlantic forcing constitute a cross-basin seesaw pattern in SLP, manifested as an anomalous Walker circulation across the tropical Americas. The TBM appears to be part of the low-level branch of the anomalous Walker circulation, which modulates Central American wind jets by orographic effect. This study highlights the seasonality of gap wind variability, and calls for further research into its influence on regional climate.
\end{abstract}

\section{Introduction}

Gaps in the Central American mountain range cause three surface wind jets directing toward the Gulfs of Tehuantepec, Papagayo, and Panama (Chelton et al. 2000a; Xie et al. 2005). The northernmost Tehuantepec wind jet is mainly modulated by cold air coming from the midlatitudes as revealed from satellite observations (Chelton et al. 2000a) and mesoscale model simulations (Steenburgh et al. 1998). The prevailing northeastern trades blow from the

Supplemental information related to this paper is available at the Journals Online website: https://dx.doi.org/10.1175/ JCLI-D-17-0021.s1.

Corresponding author: Xiaopei Lin, linxiaop@ouc.edu.cn
Caribbean Sea and funnel through Papagayo and Panama to form the other two wind jets (Chelton et al. 2000a). The climatological gap winds are strongest during boreal winter (Romero-Centeno et al. 2003; Xie et al. 2005), although the westward extension and intensification of the Azores-Bermuda high accelerate the Tehuantepec and Papagayo jets slightly in midsummer (Romero-Centeno et al. 2007; Small et al. 2007). These jets affect the northeastern tropical Pacific Ocean by modulating the sea surface temperature (SST) annual cycle (Sun and Yu 2006), strengthening turbulent mixing (Liang et al. 2009), and driving regional ocean circulations (Kessler 2006) and eddies (Chang et al. 2012). They also influence the location of the intertropical convergence zone (Xu et al. 2005) and the development of atmospheric disturbances (Holbach and Bourassa 2014). 
Although the climatological gap winds have been studied extensively, few studies have focused on their interannual variability. Romero-Centeno et al. (2003) used a statistical model to reconstruct the Tehuantepec gap winds and found an El Niño-Southern Oscillation (ENSO) effect with some asymmetries between positive and negative episodes (only statistically significant for May and September during El Niño years). Karnauskas et al. (2008) found that the Atlantic tripole pattern is more important than ENSO for the Tehuantepec jet variability while ENSO and other local factors affect fluctuations in the Papagayo jet. During boreal winter when ENSO peaks, all the Central American gap winds exhibit merely modest differences between El Niño and La Niña events, and ocean thermocline depth change due to coastal Kelvin waves coming from the equator is more important for SST variability in these gap wind regions than local wind variability (Alexander et al. 2012). According to Zamudio et al. (2006), the coastally trapped waves also modulate interannual variability of the Tehuantepec eddies during El Niño years in the absence of substantial local wind anomalies. While these studies imply that ENSO forcing is not strong for fluctuations in the gap winds, Karnauskas et al. (2008) pointed out that summertime Papagayo gap wind variability is more closely related to the Niño-3 index than that in wintertime. This implies a seasonality of the ENSO effect in the region, although its mechanism remains unclear.

Here, we investigate the seasonality and mechanism of interannual variability in gap winds. The leading empirical orthogonal function (EOF) mode of wind variability over the Intra-Americas Seas across Central America captures the main characteristics of Central American gap wind variability, especially that in the Papagayo jet. Interestingly, this gap wind mode peaks in late summer, although ENSO is strongest in boreal winter (Rasmusson and Carpenter 1982). In addition to ENSO, tropical Atlantic SST variability in boreal summer is a secondary forcing of this gap wind mode. The goal of this study is to clarify the relationship between these large-scale forcings and the gap wind mode, and to build a bridge between the gap wind variability and anomalous large-scale circulation. Furthermore, we find that the gap wind mode constitutes the lower branch of an anomalous Walker circulation between the Pacific and Atlantic. Our analysis implies that orographic effect could substantially affect surface wind under the anomalous Walker circulation.

The rest of this paper is organized as follows. Section 2 introduces datasets and methods used in this study. The definition and some basic characteristics of the leading mode of the Central American gap wind variability are shown in section 3. Section 4 presents results on the relationship of the leading gap wind mode with ENSO and the tropical Atlantic. In section 5, we summarize our findings and discuss the relationship between the gap wind mode and the anomalous Walker circulation linking the Pacific and Atlantic.

\section{Data and methods}

We use several reanalysis datasets to investigate the interannual variability of the Central American gap winds. We use monthly 1000-mb winds from 1979 to 2010 from the Climate Forecast System Reanalysis $\left(\right.$ CFSR; $\left.0.5^{\circ} \times 0.5^{\circ}\right)($ Saha et al. 2010$)$ of the National Centers for Environmental Prediction (NCEP). The 10-m winds from CFSR 1-h forecasts are employed to study the seasonality of wind vector and wind stresses. Other reanalysis datasets (10-m winds) with lower spatial resolution, such as the ERA-Interim (ERA-I; $0.75^{\circ} \times$ $0.75^{\circ}$ ) monthly mean reanalysis (Dee et al. 2011), the NCEP-National Center for Atmospheric Research (NCAR) Reanalysis 1 (NCEP1; Kalnay et al. 1996; $\left.2.5^{\circ} \times 2.5^{\circ}\right)$ and the NCEP-Department of Energy (DOE) Reanalysis 2 (NCEP2; Kanamitsu et al. 2002; $2.5^{\circ} \times 2.5^{\circ}$ ) from 1979 through 2014 yield similar results regarding the leading EOF modes of surface wind variability. A cross-calibrated multiplatform (CCMP; $0.25^{\circ} \times 0.25^{\circ}$ ) winds product (Atlas et al. 2011) from 1988 to 2011, which blends surface wind data from SSM/I, TMI, AMSR-E, QuikSCAT, and SeaWinds on ADEOS-II by cross-calibration and assimilation, shows generally similar results compared to these reanalysis datasets. Some minor differences (as will be briefly discussed in section 3) among these datasets do not influence our main conclusions. Only the results using CFSR will be shown in this study. Monthly sea level pressure (SLP), 200- and 850-hPa winds, 500-hPa vertical velocity, and 200-hPa geopotential heights are obtained from CFSR to investigate the large-scale forcing of this mode. Results using ERA-I, NCEP1, and NCEP2 are also similar and will not be shown. SST data are taken from the Hadley Centre Sea Ice and Sea Surface Temperature (HadISST) dataset (Rayner et al. 2003).

To reduce subseasonal and decadal variabilities, a 4-month- to 8-yr bandpass Butterworth filter (Parks and Burrus 1987) is applied onto these datasets after removing the monthly climatology and linear trend. This filter was used to isolate ENSO signals (Zhang et al. 2013). Three rectangular areas are selected as in Figs. 1 and 2 a to represent the Tehuantepec, Papagayo, and Panama gap wind variability; the first two regions follow Karnauskas et al. (2008). Considering their major directions, the zonal component of the Papagayo winds 
(a) DJF

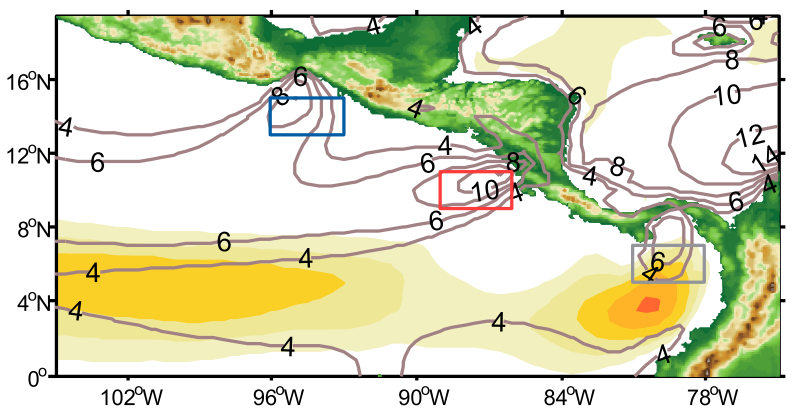

(b) JAS

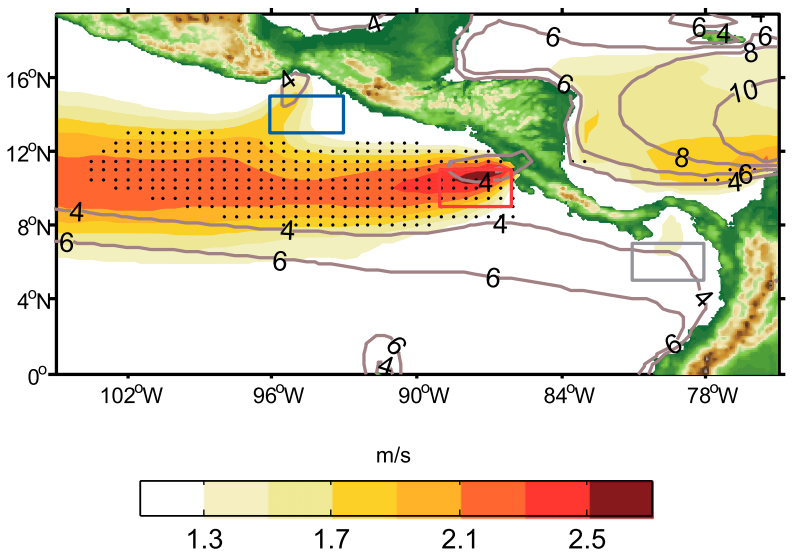

FIG. 1. Climatology of 1000-mb wind speed $\left(\mathrm{m} \mathrm{s}^{-1}\right.$, contoured) and monthly STD of $1000-\mathrm{mb}$ wind vector $\left(\mathrm{m} \mathrm{s}^{-1}\right.$, color shaded) averaged in (a) DJF and (b) JAS. Three rectangles indicate the regions used to make the indices of the Tehuantepec (blue), $\mathrm{Pa}$ pagayo (red) and Panama (gray) gap wind variabilities. Dots in (b) indicate the region where the correlation coefficients of anomalous 1000-mb zonal winds and the Papagayo gap wind index are greater than 0.8 . All values are calculated using CFSR.

and meridional component of the Tehuantepec and Panama jets are utilized as their indices. These indices are calculated by averaging the monthly prevailing wind component in the corresponding box of these gap winds.

\section{Transbasin mode}

Figure 1 shows wind speed and standard deviation (STD) of surface winds over Central America and adjacent seas during December-February (DJF) and JulySeptember (JAS). Although the Papagayo gap wind speed is strongest during DJF, the variance of wind vector (calculated by the sum of the STD of zonal and meridional wind components) is moderate in this season (Fig. 1a). If ENSO plays a leading role (Karnauskas et al. 2008), one may expect that the Papagayo jet shows a maximum variance in the peak season of ENSO. However, the fluctuation in the Papagayo jet shows the maximum STD in JAS (Fig. 1b), different from the result of Karnauskas et al. (2008) that this jet variability is the strongest during boreal winter. The reason might be that they used wind stress datasets whereas this study used wind vector datasets. We convert the wind vector to wind stresses by the quadratic stress law, in which the wind stress is proportional to the square of $10-\mathrm{m}$ wind speed (e.g., McGregor et al. 2012). Since there are no 10-m winds analyzed by CFSR, we use 10-m winds from CFSR 1-h forecasts, which show very similar variability and seasonality to $1000-\mathrm{mb}$ winds, to study the difference between wind vector and wind stresses. The monthly STD of Papagayo wind stress is indeed strongest in boreal winter (see Fig. S1a in the supplemental material for raw and 4 months -8 years bandpass filtered data). The climatological wind speed difference in Papagayo between boreal winter $\left(-6.34 \mathrm{~m} \mathrm{~s}^{-1}\right.$ for zonal wind $U$ and $-4.83 \mathrm{~m} \mathrm{~s}^{-1}$ for meridional wind $V$ in February) and boreal summer $\left(-2.15 \mathrm{~m} \mathrm{~s}^{-1}\right.$ for $U$ and $-1.13 \mathrm{~m} \mathrm{~s}^{-1}$ for $V$ in August) causes the difference in monthly STD between wind vector and wind stresses (Fig. S1a). For example, a zonal (meridional) wind anomaly of $-1 \mathrm{~m} \mathrm{~s}^{-1}$ with climatological wind speed in August leads to a $5.31(3.26) \mathrm{m}^{2} \mathrm{~s}^{-2}$ anomaly of wind speed squared, whereas the same wind speed anomaly in (a) $\operatorname{EOF} 1(39.90 \%)$

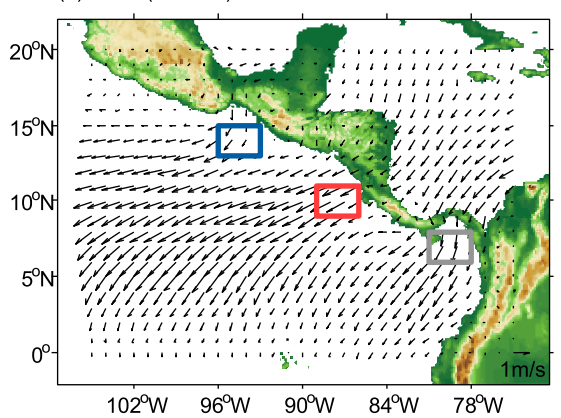

(b) STD

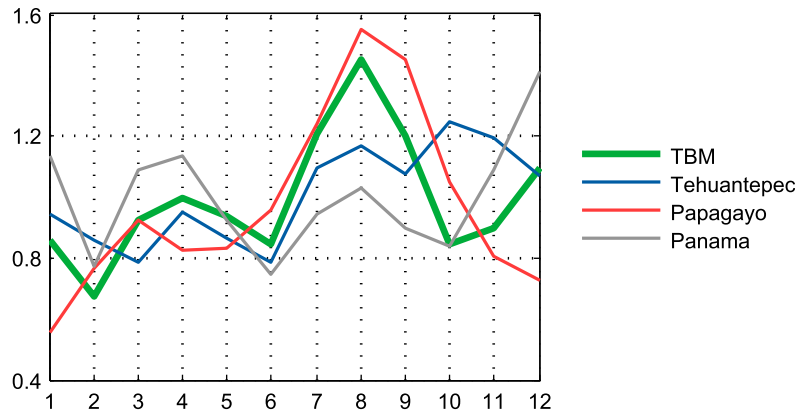

FIG. 2. (a) The first EOF pattern of $1000-\mathrm{mb}$ wind anomaly over the Intra-Americas Seas across Central America (the TBM). The three rectangles indicate the regions used to make the indices of the Tehuantepec (blue), Papagayo (red), and Panama (gray) gap wind variabilities. (b) Monthly STD of the normalized TBM (green), Tehuantepec (blue), Papagayo (red), and Panama (gray) indices. All values are calculated using CFSR. 
(a) correlation of SST and TBM
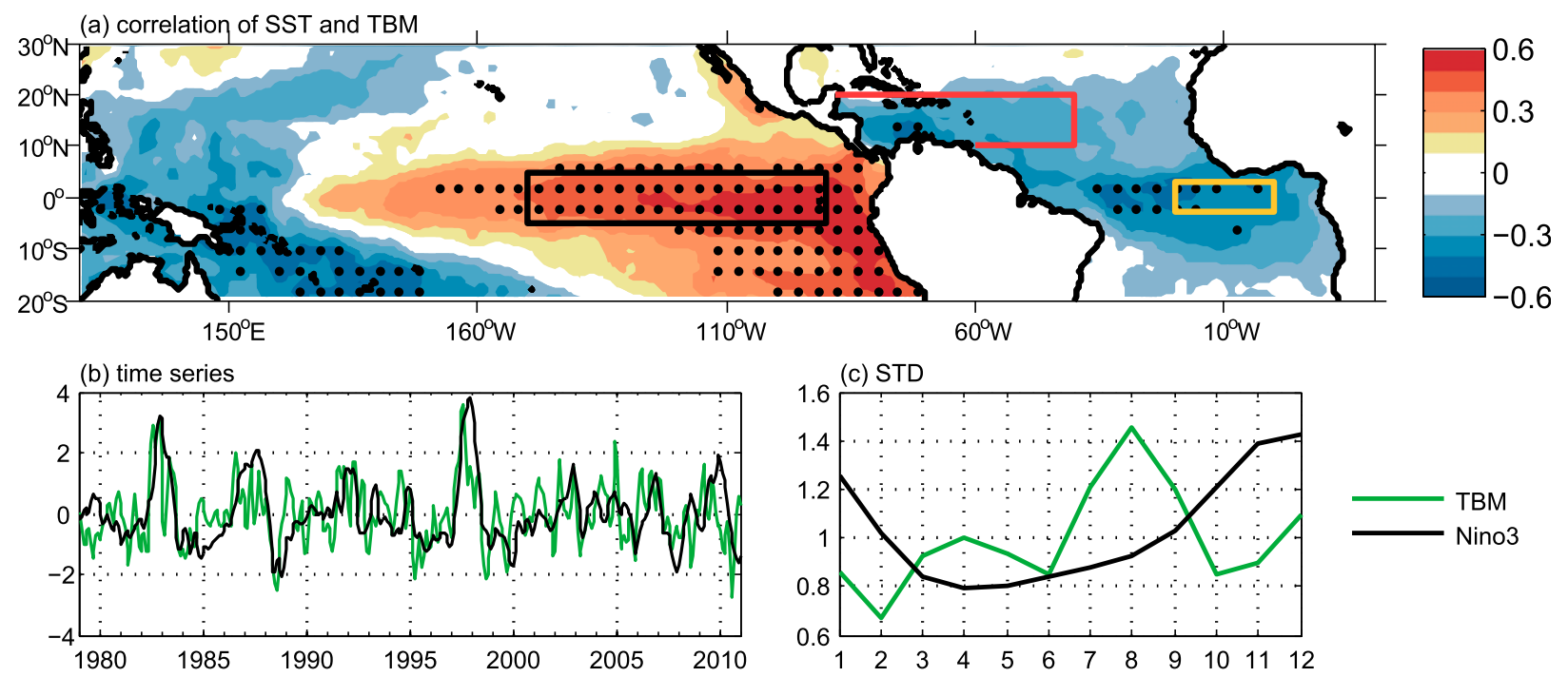

FIG. 3. (a) Correlation map of SST anomaly and the TBM index. Dots designate correlation coefficients exceeding $95 \%$ statistical confidence using the two-tailed Student's $t$ test. Three rectangles indicate the regions used to make the indices of the Niño-3 (black), ATL3 (yellow), and Caribbean SST (red) indices. Note that the Caribbean SST index is averaged SST anomaly only in the Atlantic Ocean. (b) Monthly normalized time series of the TBM (green) and Niño-3 (black) indices and (c) their monthly STD. SST and the Niño-3 index are taken from HadISST, and the TBM index is calculated using CFSR.

February could lead to a $13.68(10.66) \mathrm{m}^{2} \mathrm{~s}^{-2}$ anomaly of wind speed squared. Although the Papagayo wind vector fluctuation (i.e., zonal and meridional wind fluctuations) is stronger in August than in February (Fig. S1b), because of the smaller climatological wind speed the wind stress fluctuation is weaker in August than in February (Fig. S1c). The 10-m winds of ERA-I (19792010, the same time period as for CFSR) show similar results (see Fig. S2 and its caption). Hereafter we focus on the wind vector variability.

In JAS, wind variance is large in a zonal band extending from Papagayo westward over the Pacific Ocean (Fig. 1b), where the zonal wind correlation with the Papagayo wind index (defined in section 2) is consistently high. In comparison, correlation does not show a comparable value in the Caribbean Sea, suggesting that the strong gap wind variability in Papagayo is not simply due to Atlantic trade wind variability propagating downstream into the Pacific Ocean but is strongly influenced by the orographic effect of the Central American mountain range. We apply an EOF method to both the meridional and zonal components of monthly surface winds over the Intra-Americas Seas across Central America $\left(0^{\circ}-20^{\circ} \mathrm{N}, 105^{\circ}-75^{\circ} \mathrm{W}\right)$ to depict the main wind variabilities in this region. Chelton et al. (2000b) applied an EOF method to a similar domain to study high-frequency gap wind variability (their Figs. 17 and 18). The first EOF mode accounts for $39.90 \%$ of the variance (Fig. 2a). Results are insensitive for moderate changes in the domain and robust among different datasets (Fig. S3). We define this EOF mode as a transbasin mode (TBM), which shows anomalous trade winds blowing from the Atlantic into the northeastern tropical Pacific Ocean through the Central American isthmus. The principal component of the first EOF mode is defined as the TBM index. This index is highly anticorrelated with the Papagayo $(r=-0.86)$ and Panama $(r=-0.83)$ jet indices, and moderately with the Tehuantepec $(r=-0.49)$ index. This implies that variability in all these wind jets is associated with this surface wind mode. The Papagayo wind index exhibits a seasonality peaking in JAS that is the same as the EOF mode of the broad domain whereas the Tehuantepec and Panama jet variabilities feature different seasonalities (Fig. 2b). Thus, the TBM captures well the Papagayo jet variability.

\section{Large-scale forcing}

To identify the large-scale forcing of the TBM, we calculate the correlation of SST anomaly with the monthly TBM index (Fig. 3a). It exhibits an SST seesaw relationship between the eastern tropical Pacific and the tropical Atlantic, with an El Niño-like pattern over the Pacific and negative anomalies over the Atlantic. Previous research has shown a similar Pacific-Atlantic seesaw relationship (Wang 2006) in boreal summer associated with various phenomena, such as Caribbean rainfall (Giannini et al. 2000), the Caribbean low-level jet (CLLJ; Muñoz et al. 2008), and the Great Plains 
(a) JAS SST

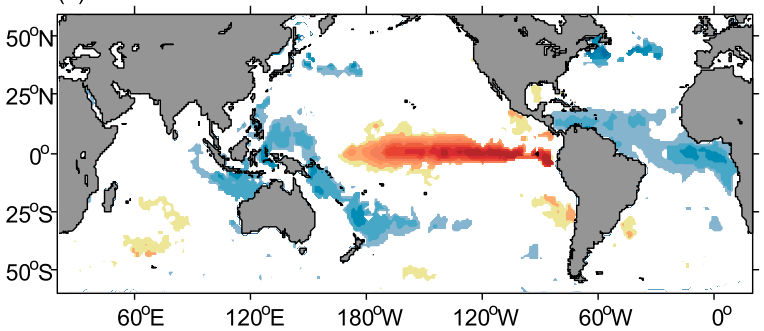

(c) DJF SST

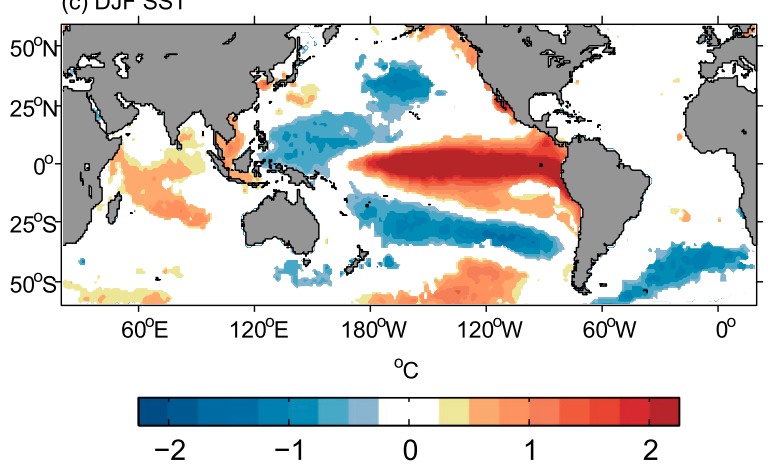

(b) JAS SLP/wind

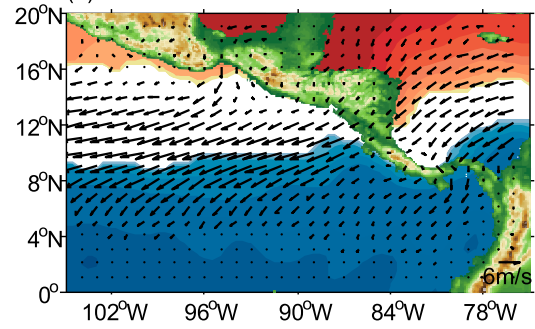

(d) DJF SLP/wind

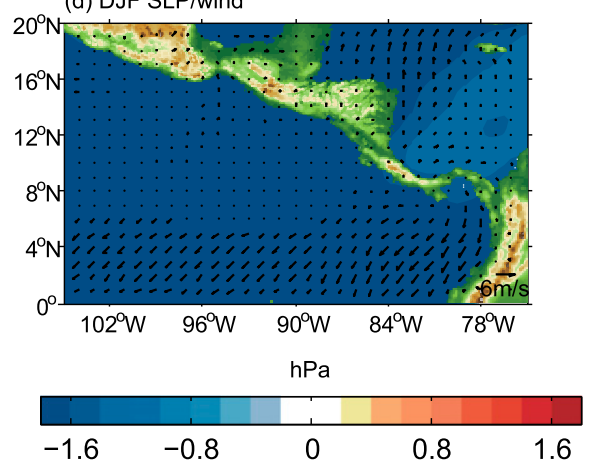

FIG. 4. Composite maps of anomalous SST $\left({ }^{\circ} \mathrm{C}\right.$, color shaded) during (a) JAS and (c) DJF (December in a TBM year and January and February in the next year). Composite maps of $1000-\mathrm{mb}$ winds $\left(\mathrm{m} \mathrm{s}^{-1}\right)$ and SLP (hPa; color shaded) during (b) JAS and (d) DJF. All values are shown as the mean values averaged in JAS (DJF) for +1 STD TBM years minus mean values averaged in JAS (DJF) for -1 STD TBM years. Because DJF of the last -1 STD TBM year (2010/11 DJF) is beyond the time range of CFSR, this year is omitted in this composite map. Only values exceeding 95\% statistical confidence using the two-tailed Student's $t$ test are shown. SST is taken from HadISST; SLP, winds, and the TBM index are taken from CFSR.

low-level jet (Krishnamurthy et al. 2015). The SST correlation is higher in the Pacific than that in the Atlantic, suggesting the leading role of ENSO in this gap wind mode.

\section{a. ENSO forcing}

Figure $3 \mathrm{~b}$ compares the monthly Niño-3 index (SST anomaly averaged over $5^{\circ} \mathrm{S}-5^{\circ} \mathrm{N}, 150^{\circ}-90^{\circ} \mathrm{W}$ as in Fig. 3a) and the TBM index. The concurrent correlation between the two indices is moderate $(r=0.50)$ because of a phase shift between them (e.g., in 1997/98). ENSO peaks in boreal winter whereas the TBM peaks in JAS (Fig. 3c). Reasons for the phase shift between ENSO and the TBM will be discussed. We select positive (negative) TBM years when the normalized TBM index averaged in JAS exceeds $+1(-1)$ STD. This criterion selects 1982, 1986, 1991, and 1997 as positive TBM years and 1988, 1995, 1998, 1999, 2008, and 2010 as negative TBM years, using CFSR. While the selected TBM years are not identical in other datasets (not shown), our main conclusions are robust. Most selected TBM years are accompanied by ENSO at the end of the year (Fig. S4), which highlights the importance of ENSO to the TBM. During the peak season (JAS) of TBM years, the spatial distributions of anomalous SST (Fig. S5), SLP, and surface winds (Fig. S6) share common features, implying that there are some common large-scale forcings. To isolate the common large-scale forcings, we average variables in the positive and negative TBM years, respectively, and then calculate their differences to make composite maps. Considering that the climatological wind field in TBM domain in September is different from that in July-August (e.g., Romero-Centeno et al. 2007), we also use July-August for the analysis and the results are similar. Results are also similar if the JAS Niño-3 index is used.

In JAS, a developing El Niño with anomalous warm waters extending westward from the coast of South America dominates the tropical Pacific, with a weak negative Atlantic Niño-like (Zebiak 1993; Keenlyside and Latif 2007) pattern and anomalous cold Caribbean Sea (Fig. 4a). In response to the SST anomalies, SLP features a seesaw relationship between the two tropical ocean basins (Muñoz et al. 2008). Central America sits on the boundary of anomalous Atlantic high pressure in the north and anomalous Pacific low pressure in the south (Giannini et al. 2000). This pattern renders the anomalous strong meridional and weak cross-isthmus 
(a) velocity potential and divergence winds

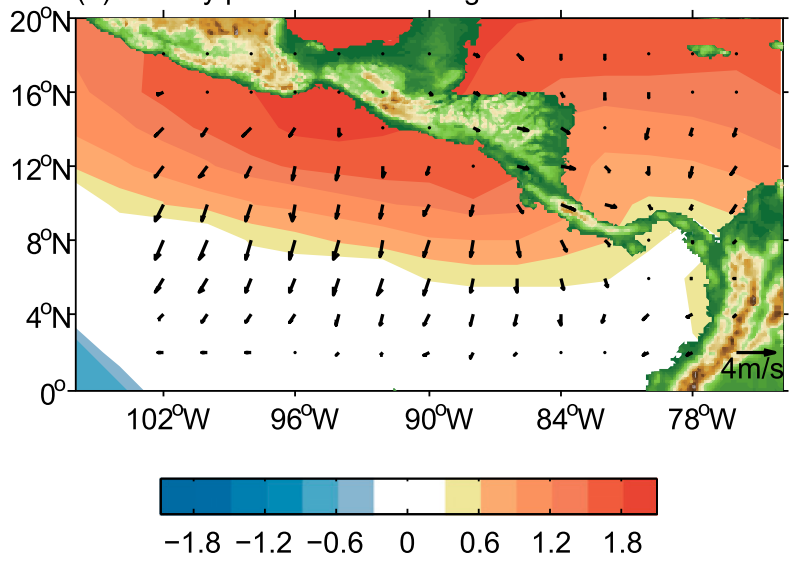

(b) stream function and vorticity winds
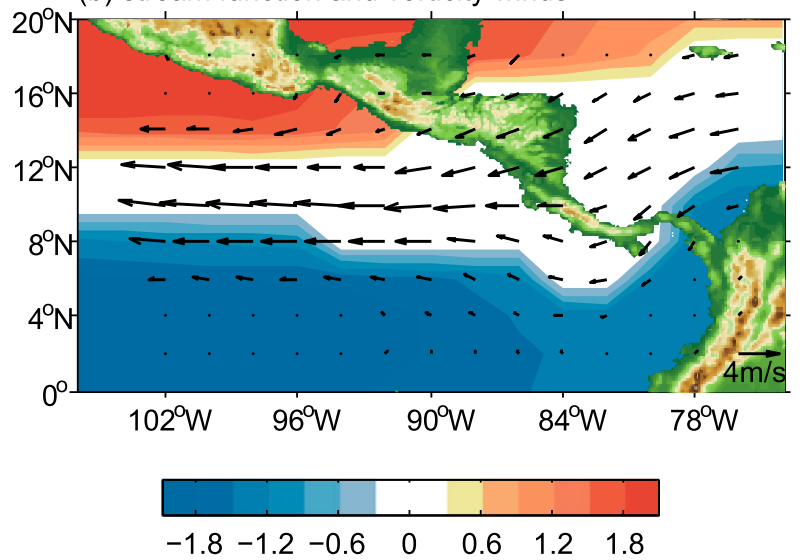

FIG. 5. Composite maps of anomalous (a) velocity potential $\left(10^{6} \mathrm{~m}^{2} \mathrm{~s}^{-1}\right)$ and divergence winds $\left(\mathrm{m} \mathrm{s}^{-1}\right)$ and (b) streamfunction $\left(10^{6} \mathrm{~m}^{2} \mathrm{~s}^{-1}\right)$ and vorticity winds $\left(\mathrm{m} \mathrm{s}^{-1}\right)$ of $1000-\mathrm{mb}$ winds in JAS. All values are shown as the mean values averaged in JAS for +1 STD TBM years minus mean values averaged in JAS for -1 STD TBM years. Only values exceeding $95 \%$ statistical confidence using the two-tailed Student's $t$ test are shown. All values are calculated using CFSR.

SLP gradients near Papagayo (Fig. 4b). The zonal wind anomalies are in geostrophic balance with SLP anomalies while the meridional wind anomalies are ageostrophic. The pattern of anomalous velocity potential associated with divergence winds (Fig. 5a) is weak in the Gulf of Papagayo and Gulf of Panama, while causing meridional wind anomalies in the Gulf of Tehuantepec. The magnitude of the geostrophic component (cf. Figs. $5 \mathrm{~b}$ and $5 \mathrm{a}$ ) is much larger than the ageostrophic component $\left(\sim 4.6 \mathrm{~m} \mathrm{~s}^{-1}\right.$ vs $1.7 \mathrm{~m} \mathrm{~s}^{-1}$ in the Gulf of Papagayo). Anomalous vorticity winds from the Caribbean Sea are amplified when blowing through the Isthmus of Papagayo (Fig. 5b). The orographic effects are weak in other gaps due to the north-south orientation, which is inconsistent with the direction of the anomalous vorticity winds. Anomalous Caribbean trades turn into easterlies over the tropical Pacific, in geostrophy with the SLP anomaly contours (Fig. 4b).

During JAS, there is an anomalous rising motion slightly north of the equator in the eastern tropical Pacific (Fig. 6a), anchored by anomalously warm SST in this region (Fig. 4a). Through an anomalous Walker circulation between the tropical Pacific and Atlantic, there are anomalous descending motions in the northern tropical Atlantic. As Giannini et al. (2000) hypothesized, in response to this ENSO-induced perturbation, Central America exhibits anomalous descending motion and surface divergence. Because of the baroclinic nature of tropical atmospheric response, this distribution of vertical motion contributes to the formation of the anomalous meridional SLP gradient across Central America and the TBM in boreal summer. Muñoz et al. (2008) noted that, during El Niño events, the enhanced meridional SLP gradient accelerates the Atlantic trade winds and in turn cools SST underneath by strengthening upwelling and turbulent heat flux in the Caribbean Sea. The colder SST could further enhance the high SLP anomaly north to the Isthmus of Papagayo and the anomalous meridional SLP gradient across Central America. The upper layer geopotential height anomaly is relatively weak, suggesting a weak effect of atmospheric teleconnection in boreal summer. GCMs reproduce this preference for the warm season of cross-Central American wind response to ENSO (Fig. 7 of Xie and Zhou 2017) as a result of the modulations by the seasonally variable background state.

Composite maps in the following DJF illustrate why the TBM is weak during the peak season of ENSO. During DJF, ENSO reaches its mature phase (Fig. 4c) with enhanced deep convection in the central and eastern tropical Pacific (Fig. 6b). Through the atmosphere bridge (Alexander et al. 2002) associated with the ENSO-induced anomalous deep convection, the tropical Atlantic warms (too weak to appear in Fig. 4c) and the SST seesaw pattern between the Pacific and Atlantic disappears, although this mechanism is not robust in the equatorial and southern tropical Atlantic (Chang et al. 2006). The basin-scale SLP anomaly seesaw pattern still exists in boreal winter as part of the anomalous Walker circulation between the two ocean basins (Wang 2005). Across Central America, anomalous SLP on the Atlantic side is of the same sign as that in the eastern tropical Pacific, resulting in weak SLP gradient anomalies and weak TBM variability (Fig. 4d). This pattern of SLP anomaly is the result of anomalous large-scale circulation during boreal winter. The 200-hPa geopotential height anomalies manifest a prominent Matsuno-Gilltype pattern (Matsuno 1966; Gill 1980) over the tropical Pacific (Fig. 6b). This pattern includes a pair of Rossby 
(a) JAS

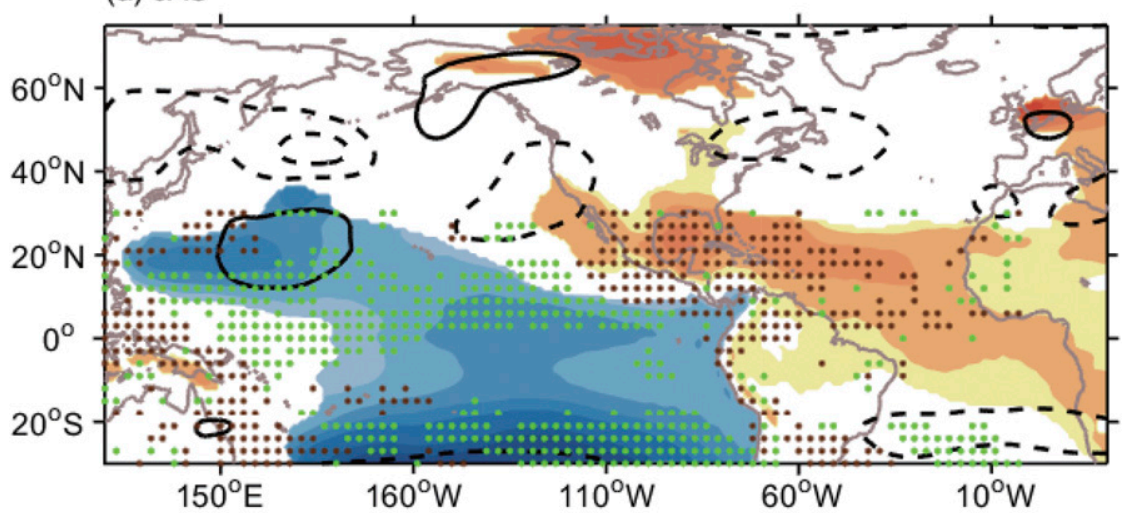

(b) DJF

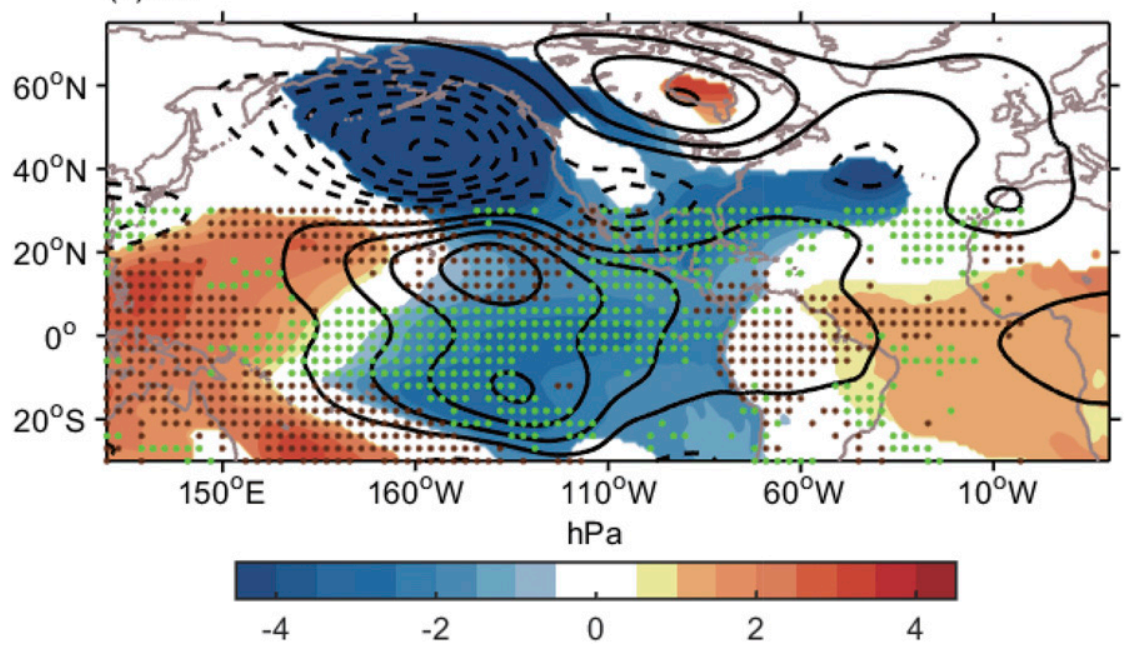

FIG. 6. Composite maps of anomalous SLP (color shaded), 200-hPa geopotential height (contours range from -150 to $120 \mathrm{gpm}$ with a contour level of $30 \mathrm{gpm}$; the zero line is omitted, positive contours are solid and negative contours are dashed), and 500-hPa vertical velocity (green dots designate values lower than $-0.01 \mathrm{~Pa} \mathrm{~s}^{-1}$ and brown dots designate values larger than $0.01 \mathrm{~Pa} \mathrm{~s}^{-1}$; only shown south of $30^{\circ} \mathrm{N}$ ) in (a) JAS and (b) DJF. All values are shown as the mean values averaged in JAS (DJF) for +1 STD TBM years minus mean values averaged in JAS (DJF) for -1 STD TBM years. Because DJF of the last - 1 STD TBM year (2010/11 DJF) is beyond the time range of CFSR, this year is omitted in this composite map. Only values exceeding 95\% statistical confidence using the two-tailed Student's $t$ test are shown for SLP anomaly. All values are taken from CFSR.

waves off the central equatorial Pacific and equatorial Kelvin waves propagating toward the western tropical Atlantic. In addition, ENSO induces the Pacific-North American (PNA) teleconnection (Horel and Wallace 1981; Wallace and Gutzler 1981). Together with the equatorial Kelvin waves, the low pressure center of the PNA pattern over the southern United States reduces the anomalous cross-Central American SLP gradient, suppressing the TBM variability.

\section{b. Tropical Atlantic forcing}

Although ENSO forcing explains much of the TBM, it fails to account for significant correlations between the tropical Atlantic SST anomaly and the TBM (Fig. 3a). When we just focus on the peak season of the TBM (JAS), the TBM index exhibits comparable correlations with the tropical Pacific and Atlantic SST anomalies (Fig. S7a). The tropical Atlantic appears to have an independent effect on this gap wind mode. Upon close inspection, the Atlantic SST forcing of the TBM exhibits two centers, the equatorial Atlantic and the Caribbean Sea (Fig. 3a). The equatorial Atlantic signal, adjoining to the western coast of Africa, is consistent with the pattern of the Atlantic Niño (Zebiak 1993; Keenlyside and Latif 2007). SST and SLP anomalies in the Caribbean Sea during summertime could be influenced by the 
(a) total

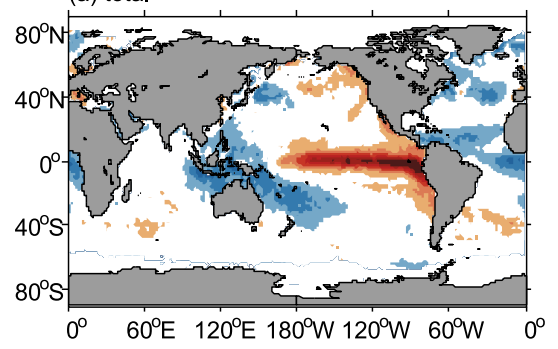

(d) ATL3 (0 year)

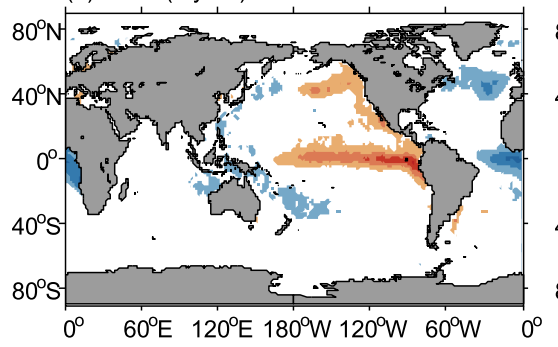

(b) Nino3 (-1 year)

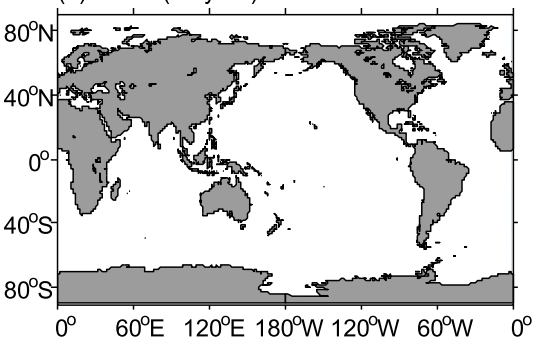

(e) Caribbean SST (0 year)

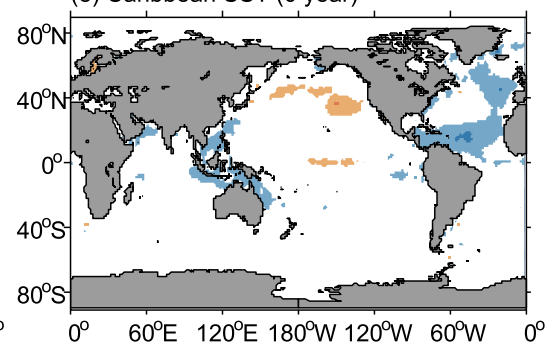

(c) Nino3 (0 year)

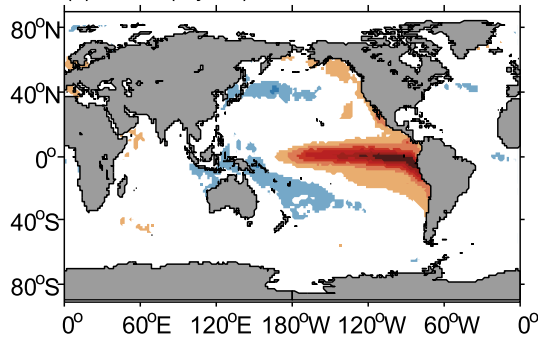

${ }^{\circ} \mathrm{C}$

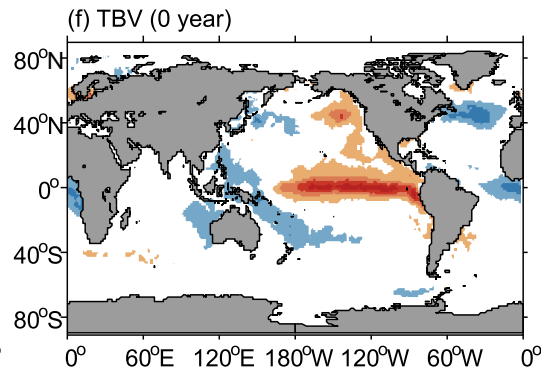
.

\begin{tabular}{lllllll|}
\hline & & & & & & \\
\hline-1.5 & -1 & -0.5 & 0 & 0.5 & 1 & 1.5 \\
\hline
\end{tabular}

FIG. 7. Composite SST $\left({ }^{\circ} \mathrm{C}\right)$ anomaly in (a) the total values and (b)-(f) linear regressions explained by various indices. Linear regression is shown against the Niño-3 index in (b) November-February (NDJF) prior to the TBM year and in (c) JAS of the concurrent year, and against the ATL3 index in concurrent JAS in (d), the Caribbean SST index in concurrent JAS in (e), and the TBV index in concurrent JAS in (f). All values are shown as the mean values averaged in JAS for +1 STD TBM years minus mean values averaged in JAS for -1 STD TBM years. Only values exceeding 95\% statistical confidence using the two-tailed Student's $t$ test are shown. SST and SST indices are calculated by HadISST, and other values and indices are calculated by CFSR.

interannual variability of the Atlantic warm pools (Wang et al. 2006, 2008). A strong ENSO event in boreal winter could also influence the northern tropical Atlantic SST until the following summer (Curtis and Hastenrath 1995; Enfield and Mayer 1997; Alexander and Scott 2002) when this event continues throughout January-March (Lee et al. 2008). Because so many factors could influence the tropical Atlantic SST and the $\mathrm{TBM}$, we do linear regression analysis to give a preliminary assessment of the Atlantic forcing.

Figures 7 and 8 are composite maps (+1 STD minus -1 STD TBM years) of (a) total values and (b)-(f) linear regression explained by various indices in JAS. The effect of preceding ENSO is evaluated by using the Niño-3 index averaged from November in the prior year to February in the year concurrent with a TBM event. This effect of the preceding ENSO is negligible for TBM (Figs. 7b and 8b). Results using the Niño-3 index averaged in January-March of the TBM year following Lee et al. (2008) are similar. Only the 1997/98 El Niño event affects Caribbean SST and the TBM in JAS of 1998. While concurrent developing ENSO events are a primary large-scale forcing of the TBM (section 4a; Figs. 7c and $8 \mathrm{c}$ ), not all the TBM events are accompanied by developing ENSO (Fig. S5). Thus, other forcings independent of ENSO play a role.

The Atlantic Niño, measured by the ATL3 index [defined by Zebiak (1993); SST anomaly averaged over $3^{\circ} \mathrm{S}-3^{\circ} \mathrm{N}, 20^{\circ} \mathrm{W}-0^{\circ}$, shown in Fig. 3a], shows a weak seesaw relationship with Pacific ENSO (e.g., Wang 2006; Rodríguez-Fonseca et al. 2009; Ding et al. 2012; see also our Fig. 7d) and contributes to the TBM (Fig. 8d). The Caribbean SST anomaly (we define it as SST anomaly averaged over $10^{\circ}-20^{\circ} \mathrm{N}$, from the eastern coast of America to $40^{\circ} \mathrm{W}$ in the Atlantic Ocean, shown in Fig. 3a) is independent of concurrent SST anomalies in other regions (Fig. 7e) and contributes to the TBM (Fig. 8e). As Muñoz et al. (2008) found, SST and SLP anomalies in the Caribbean Sea during summertime may also be a response to remote SST forcing that leads by one or two months. We test the correlation between the JAS TBM index and 3-month-averaged SST anomaly leading by one or two months (Figs. S7b and S7c). The Caribbean SST anomaly exhibits a weaker correlation with the TBM index compared to the Atlantic Niño. It suggests that the Atlantic Niño and SST anomaly in the Caribbean Sea may be related at time lags (Muñoz et al. 2008), but this relationship is beyond 
(a) total

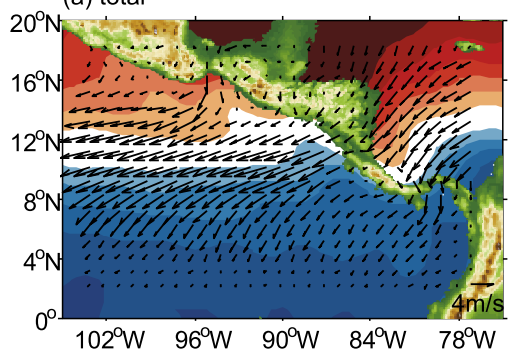

(d) Atl3 (0 year)

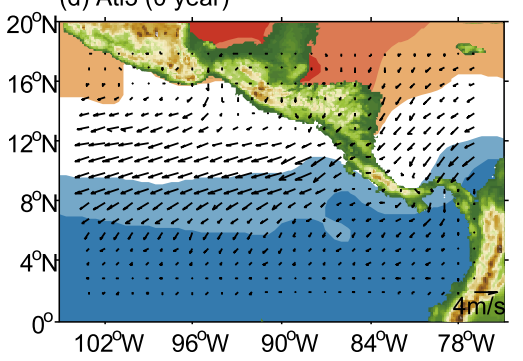

(b) Nino3 (-1 year)

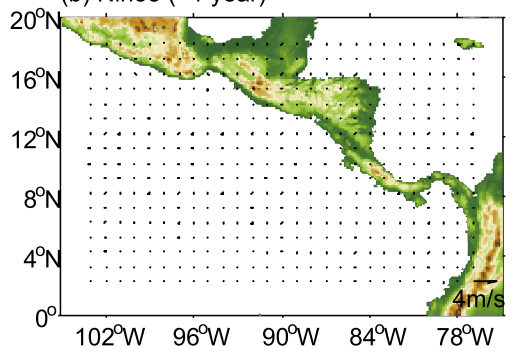

(e) Caribbean SST (0 year)

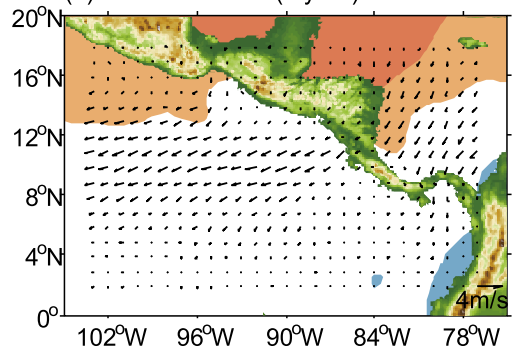

(c) Nino3 (0 year)

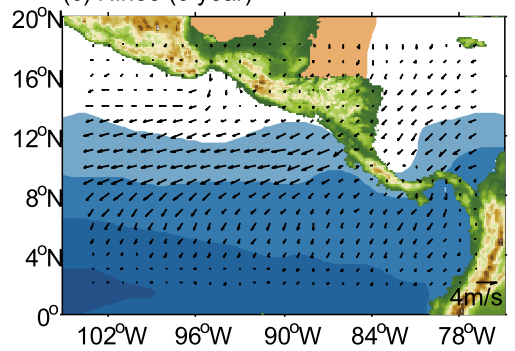

(f) TBV (0 year)

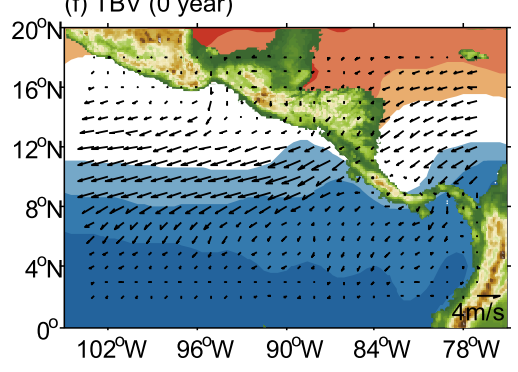

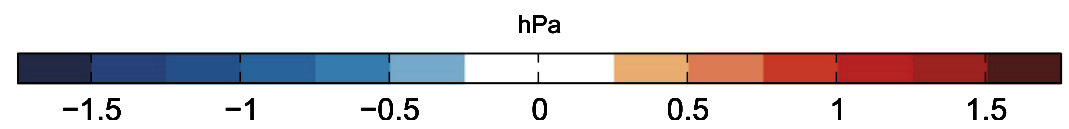

FIG. 8. As in Fig. 7, but for composite SLP (hPa, color shaded) and 1000-mb wind ( $\left.\mathrm{m} \mathrm{s}^{-1}\right)$ anomalies.

our scope of this study. The ATL3 index is more important than the Caribbean SST for summertime gap wind variability, as shown by both linear correlation $(r=-0.70$ vs -0.44 in JAS $)$ and partial correlation $(r=-0.62 \mathrm{vs}-0.30$ in JAS; correlation done after regressing out the other index) with the TBM index. However, further studies are needed to determine Atlantic contributions in the summertime TBM.

\section{c. Transbasin variability index}

Besides strong ENSO forcing, the tropical Atlantic plays an independent role in the TBM. Thus, an index including both forcings might be better than only the Niño-3 index to describe the large-scale forcing of the TBM. Such indices exist (Wang 2006; McGregor et al. 2014; Chikamoto et al. 2015) to depict the seesaw relationship between the Pacific and Atlantic. The tropical transbasin variability (TBV) index of Chikamoto et al. (2015) considers SLP variability in both oceanic basins by calculating the difference of averaged and normalized SLP anomalies between the tropical central Pacific Ocean $\left(15^{\circ} \mathrm{S}-15^{\circ} \mathrm{N}, 180^{\circ}-150^{\circ} \mathrm{W}\right)$ and the tropical Atlantic-Indian Ocean $\left(15^{\circ} \mathrm{S}-15^{\circ} \mathrm{N}, 40^{\circ} \mathrm{W}-60^{\circ} \mathrm{E}\right)$. The normalization treatment in calculating this index highlights the Atlantic contribution since SLP variability is stronger in the tropical Pacific. Figure 9a shows the TBV, TBM, and Niño-3 indices averaged in JAS (in order to facilitate their comparison, the TBV index is multiplied by -1$)$. The correlation between the TBM and TBV indices $(r=-0.72)$ is slightly higher than that between the TBM and Niño-3 indices $(r=0.69)$, as ENSO is not the leading forcing in some years. For instance, during the early 1990s, the TBM index is out of phase with the Niño-3 index, but it is in phase with the TBV index, which includes the tropical Atlantic contribution. Comparing to the total values (Figs. 7a and 8a), the TBV index explains more similar patterns of SST anomaly (Fig. 7f) and local SLP and wind anomalies (Fig. 8f) in TBM years than any other indices, especially when using ERA-I to calculate the TBV index (Figs. S8 and S9).

Then, we use monthly indices to investigate their seasonality (Fig. 9b). The winter peak of the monthly TBV index is associated with the wintertime ENSOinduced Walker circulation across the Pacific and Atlantic (Wang 2005). The TBV index also shows a summertime peak like that of the TBM index, while the ENSO index does not. Muñoz et al. (2008) showed that the CLLJ varies with the SLP seesaw pattern in boreal summer with anomalous winds blowing through Central America, suggesting that this jet variability is associated with the TBM. We find the index of this CLLJ variability (Muñoz et al. 2008; defined by $925-\mathrm{hPa}$ zonal wind averaged over $12^{\circ}-16^{\circ} \mathrm{N}$ and $70^{\circ}-80^{\circ} \mathrm{W}$ ) peaks in late summer, broadly consistent with the seasonality of the TBM. Previous studies have shown the relationship between the interannual variability of the summertime 
(a) time series

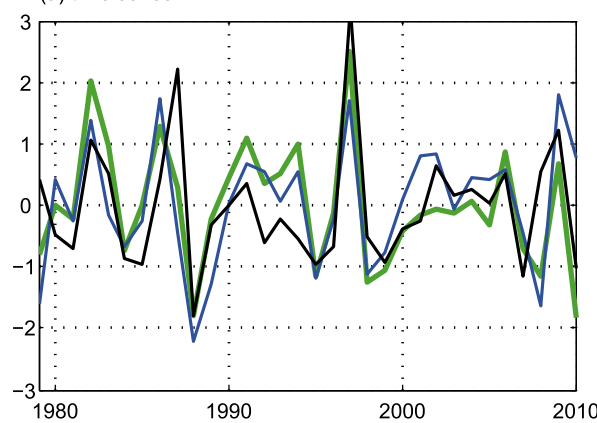

(b) STD

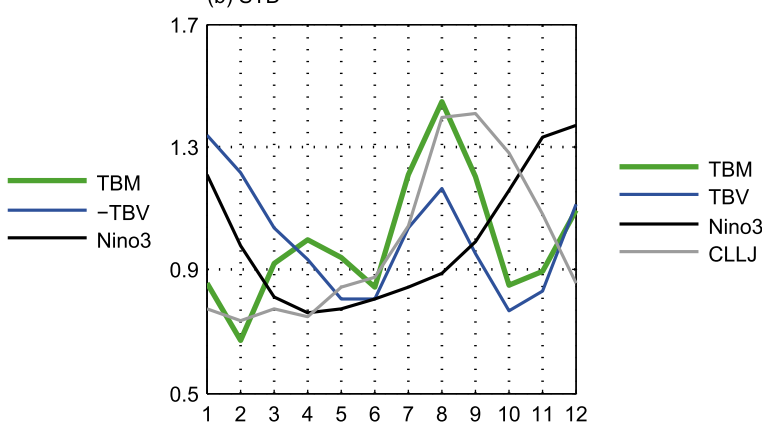

FIG. 9. (a) Annual time series averaged and normalized in JAS are shown for the TBM (green; CFSR), negative TBV (blue; CFSR) and Niño-3 (black; HadISST) indices. (b) Monthly STD of the monthly normalized TBM (green), TBV (blue), Niño-3 (black), and Caribbean low-level jet (gray; CFSR) indices.

CLLJ and many large-scale forcings, such as ENSO and the Caribbean SST anomalies (Wang 2007) and the related Atlantic warm pools (Wang et al. 2008). As the CLLJ is an important source of the trades funneling through the Central American gaps, the relationship between the CLLJ and TBM needs further study. Moreover, the correlation of monthly SST anomaly with the monthly TBV index indeed shows a seesaw pattern while the Niño-3 index does not (not shown). Since the TBV index successfully captures the summer peak of the seesaw pattern and its related low-level circulation, it tracks the TBM better than ENSO. However, as the TBV index itself is highly anticorrelated with the Niño-3 index ( $r=-0.48$, for JAS), we calculate the partial correlation of the JAS TBV and TBM indices after regressing out the concurrent Niño-3 index. The correlation coefficient $(r=-0.45)$ exhibits that the TBV index successfully captures some signals in the tropical Atlantic independent of ENSO.

The TBV does not explain all TBM variability. As an example, in 2002, both the Niño-3 and TBV indices are positive, while the TBM is nearly zero (Fig. 9a). A closer inspection suggests that in 2002, although the Niño-3 region is anomalously warm, the eastern Pacific cold tongue, with which the TBM index is highly correlated (Fig. 3a), shows no warming. The TBV index fails to depict SST anomaly in the eastern Pacific cold tongue in 2002 and some TBM years (revealed by the linear regression method). Some TBM events are not fully explained by the TBV index, which might be the result of another mechanism offsetting this large-scale forcing. Is there any other large-scale forcing or local effect (e.g., orographic effect) for the TBM? This is another important topic for future studies.

\section{Conclusions and discussion}

We have investigated interannual variability of the Central American gap winds and found that the leading mode of large-scale surface wind circulation in this region (the TBM) is associated with the Papagayo gap wind variability. Correlation analyses suggest that the TBM is associated with a SST anomaly seesaw pattern between the tropical Pacific and Atlantic (Wang 2006), related to ENSO. The TBM, however, peaks in late summer, a seasonality distinct from ENSO. We show that this difference in seasonality is due to the seasonal evolution in ENSO-induced atmospheric circulation. During JAS, an anomalous rising motion in the eastern tropical Pacific is accompanied by an anomalous descending motion in Central America in an El Niño year (Giannini et al. 2000). This anomalous circulation strengthens meridional SLP gradient across Central America, with anomalous easterlies and the accelerated Papagayo jet. In the following boreal winter as El Niño grows, the PNA pattern lowers SLP over the southern United States, weakening the SLP gradient with the equatorial Kelvin waves and suppressing the TBM. In addition to strong ENSO forcing, tropical Atlantic SST variability also contributes to the TBM, including the Atlantic Niño and Caribbean SST. The tropical Atlantic contribution also appears to peak in summertime, contributing to the SLP anomaly seesaw pattern between the Pacific and Atlantic. We further show that the index defined by Chikamoto et al. (2015) tracks the TBM better than the Niño-3 index. Since the seesaw pattern in SLP anomaly implies an anomalous Walker circulation between the Pacific and Atlantic, the relationship between the anomalous large-scale circulation and the gap wind mode should be explored.

In boreal summer, both ENSO and the Atlantic Niño could trigger an anomalous Walker circulation over South America with cross-basin SLP anomaly seesaw relationship (e.g., Wang 2005, 2006; Rodríguez-Fonseca et al. 2009; Ding et al. 2012). During TBM events, this anomalous Walker circulation is manifested by vorticity winds near the tropopause (Fig. 10a). At the same time, 


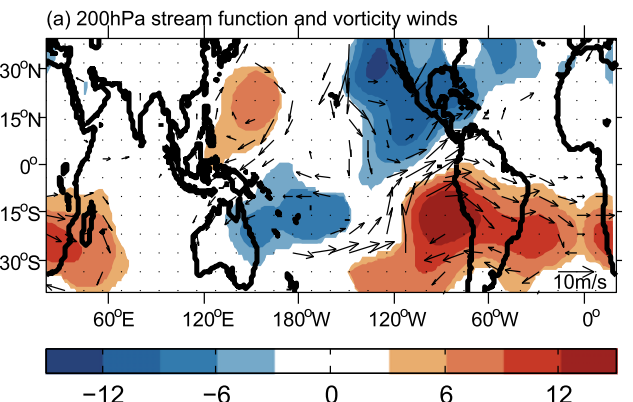

(b) $850 \mathrm{hPa}$ stream function and vorticity winds

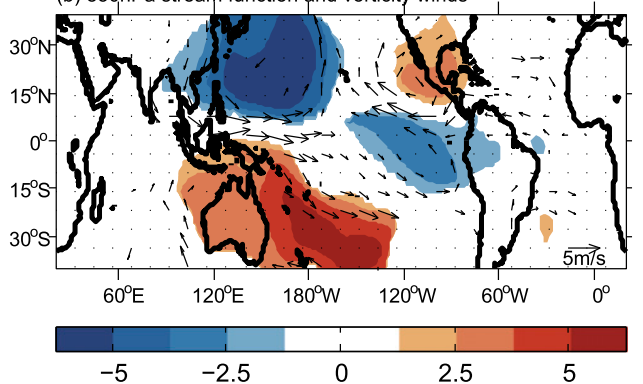

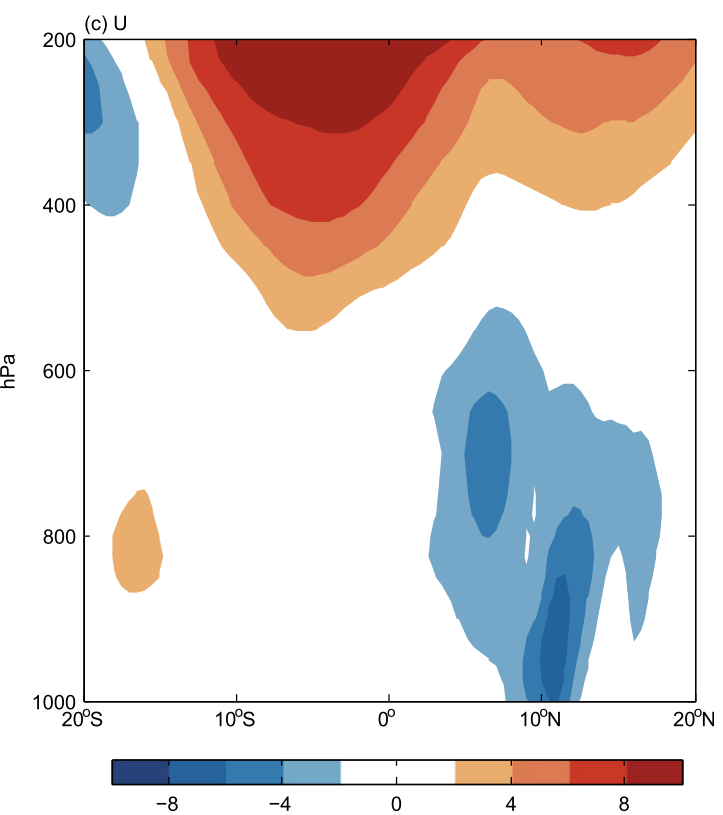

FIG. 10. Composite maps of anomalous streamfunction $\left(10^{6} \mathrm{~m}^{2} \mathrm{~s}^{-1}\right)$ and vorticity winds $\left(\mathrm{m} \mathrm{s}^{-1}\right)$ at the (a) 200-hPa and (b) 850-hPa levels in JAS. (c) Composite maps of anomalous zonal winds $\left(\mathrm{m} \mathrm{s}^{-1}\right)$ of a latitude-height cross section (zonal mean between $86^{\circ}$ and $89^{\circ} \mathrm{W}$ ) in JAS. All values are shown as the mean values averaged in JAS for +1 STD TBM years minus mean values averaged in JAS for -1 STD TBM years. Only values exceeding $95 \%$ statistical confidence using the two-tailed Student's $t$ test are shown. All values are calculated using CFSR.

an anomalous Walker circulation develops in the western equatorial Pacific. Because of the baroclinic nature of tropical atmospheric response, at the 850-hPa level, there is an anomalous equatorial jet in the opposite direction in the western equatorial Pacific (Fig. 10b). This simple two-layer baroclinic circulation fails over South America because no anomalous equatorial jet exists in the lower troposphere (Fig. 10b). The blocking effect of the high mountain range on the western coast of South America might be responsible. This effect is well illustrated by the composite map of anomalous zonal winds of a latitude-height cross section (Fig. 10c). The gaps in Central America provide narrow passages between the two tropical ocean basins in the lower troposphere. Therefore, an anomalous jet blows into the Pacific Ocean via Central America in response to low-level pressure gradient. Away from the equator, the anomalous jet satisfies the geostrophic balance with anomalous SLP gradient. The orographic effect is robust for TBM events, because most individual events exhibit low-level jet cores over Papagayo (Fig. S10). This mechanism relating the anomalous Pacific-Atlantic Walker circulation to the TBM in Central America needs further studies.

Acknowledgments. This work is supported by China's National Key Research and Development Project
(2016YFA0601803) and the National Natural Science Foundation of China (4149640014, U1406401). We thank Yu Zhang for helpful discussions and Yu Kosaka for data assistance. HadISST is provided by the Met Office Hadley Centre; ERA-I by the European Centre for Medium-Range Weather Forecasts; NCEP1 and NCEP2 by the NOAA/OAR/ESRL PSD, Boulder, Colorado, USA (http://www.esrl.noaa.gov/psd/). CFSR (https://doi.org/10.5065/D6DN438J) and CCMP (http:// rda.ucar.edu/datasets/ds744.9/) are archived at the National Center for Atmospheric Research, Computational and Information Systems Laboratory, Boulder, CO.

\section{REFERENCES}

Alexander, M. A., and J. D. Scott, 2002: The influence of ENSO on air-sea interaction in the Atlantic. Geophys. Res. Lett., 29, 1701, doi:10.1029/2001GL014347.

, I. Bladé, M. Newman, J. R. Lanzante, N.-C. Lau, and J. D. Scott, 2002: The atmospheric bridge: The influence of ENSO teleconnections on air-sea interaction over the global oceans. J. Climate, 15, 2205-2231, doi:10.1175/1520-0442(2002)015<2205: TABTIO $>2.0 . C O ; 2$.

- H. Seo, S.-P. Xie, and J. D. Scott, 2012: ENSO's impact on the gap wind regions of the eastern tropical Pacific Ocean. J. Climate, 25, 3549-3565, doi:10.1175/JCLI-D-11-00320.1.

Atlas, R., R. N. Hoffman, J. Ardizzone, S. M. Leidner, J. C. Jusem, D. K. Smith, and D. Gombos, 2011: A cross-calibrated, multiplatform ocean surface wind velocity product for 
meteorological and oceanographic applications. Bull. Amer. Meteor. Soc., 92, 157-174, doi:10.1175/2010BAMS2946.1.

Chang, C.-H., and Coauthors, 2012: East Pacific ocean eddies and their relationship to subseasonal variability in Central American wind jets. J. Geophys. Res., 117, C10001, doi:10.1029/ 2011JC007315.

Chang, P., Y. Fang, R. Saravanan, L. Ji, and H. Seidel, 2006: The cause of the fragile relationship between the Pacific El Niño and the Atlantic Niño. Nature, 443, 324-328, doi:10.1038/ nature 05053 .

Chelton, D. B., M. H. Freilich, and S. K. Esbensen, 2000a: Satellite observations of the wind jets off the Pacific coast of Central America. Part I: Case studies and statistical characteristics. Mon. Wea. Rev., 128, 1993-2018, doi:10.1175/ 1520-0493(2000)128<1993:SOOTWJ > 2.0.CO;2.

,-- , and $-2000 \mathrm{~b}$ : Satellite observations of the wind jets off the Pacific coast of Central America. Part II: Regional relationships and dynamical considerations. Mon. Wea. Rev., 128, 2019-2043, doi:10.1175/1520-0493(2000)128<2019: SOOTWJ $>2.0 . \mathrm{CO} ; 2$.

Chikamoto, Y., and Coauthors, 2015: Skilful multi-year predictions of tropical trans-basin climate variability. Nat. Commun., 6 , 6869, doi:10.1038/ncomms7869.

Curtis, S., and S. Hastenrath, 1995: Forcing of anomalous sea surface temperature evolution in the tropical Atlantic during Pacific warm events. J. Geophys. Res., 100, 15 835-15847, doi:10.1029/95JC01502.

Dee, D. P., and Coauthors, 2011: The ERA-Interim reanalysis: Configuration and performance of the data assimilation system. Quart. J. Roy. Meteor. Soc., 137, 553-597, doi:10.1002/ qj.828.

Ding, H., N. S. Keenlyside, and M. Latif, 2012: Impact of the equatorial Atlantic on the El Niño Southern Oscillation. Climate Dyn., 38, 1965-1972, doi:10.1007/s00382-011-1097-y.

Enfield, D. B., and D. A. Mayer, 1997: Tropical Atlantic sea surface temperature variability and its relation to El Niño-Southern Oscillation. J. Geophys. Res., 102, 929-945, doi:10.1029/96JC03296.

Giannini, A., Y. Kushnir, and M. A. Cane, 2000: Interannual variability of Caribbean rainfall, ENSO, and the Atlantic Ocean. J. Climate, 13, 297-311, doi:10.1175/1520-0442(2000)013<0297: IVOCRE $>2.0 . \mathrm{CO} ; 2$.

Gill, A. E., 1980: Some simple solutions for heat-induced tropical circulation. Quart. J. Roy. Meteor. Soc., 106, 447-462, doi:10.1002/qj.49710644905.

Holbach, H. M., and M. A. Bourassa, 2014: The effects of gapwind-induced vorticity, the monsoon trough, and the ITCZ on east Pacific tropical cyclogenesis. Mon. Wea. Rev., 142, 13121325, doi:10.1175/MWR-D-13-00218.1.

Horel, J. D., and J. M. Wallace, 1981: Planetary-scale atmospheric phenomena associated with the Southern Oscillation. Mon. Wea. Rev., 109, 813-829, doi:10.1175/1520-0493(1981)109<0813: PSAPAW $>2.0 . \mathrm{CO} ; 2$.

Kalnay, E., and Coauthors, 1996: The NCEP/NCAR 40-Year Reanalysis Project. Bull. Amer. Meteor. Soc., 77, 437-471, doi:10.1175/1520-0477(1996)077<0437:TNYRP>2.0.CO;2.

Kanamitsu, M., W. Ebisuzaki, J. Woollen, S.-K. Yang, J. J. Hnilo, M. Fiorino, and G. L. Potter, 2002: NCEP-DOE AMIP-II Reanalysis (R-2). Bull. Amer. Meteor. Soc., 83, 1631-1643, doi:10.1175/BAMS-83-11-1631.

Karnauskas, K. B., A. J. Busalacchi, and R. Murtugudde, 2008: Low-frequency variability and remote forcing of gap winds over the east Pacific warm pool. J. Climate, 21, 4901-4918, doi:10.1175/2008JCLI1771.1.
Keenlyside, N. S., and M. Latif, 2007: Understanding equatorial Atlantic interannual variability. J. Climate, 20, 131-142, doi:10.1175/JCLI3992.1.

Kessler, W. S., 2006: The circulation of the eastern tropical Pacific: A review. Prog. Oceanogr., 69, 181-217, doi:10.1016/ j.pocean.2006.03.009.

Krishnamurthy, L., G. A. Vecchi, R. Msadek, A. Wittenberg, T. Delworth, and F. Zeng, 2015: The seasonality of the Great Plains low-level jet and ENSO relationship. J. Climate, 28, 4525-4544, doi:10.1175/JCLI-D-14-00590.1.

Lee, S.-K., D. B. Enfield, and C. Wang, 2008: Why do some El Niños have no impact on tropical North Atlantic SST? Geophys. Res. Lett., 35, L16705, doi:10.1029/2008GL034734.

Liang, J.-H., J. C. McWilliams, and N. Gruber, 2009: High-frequency response of the ocean to mountain gap winds in the northeastern tropical Pacific. J. Geophys. Res., 114, C12005, doi:10.1029/ 2009JC005370.

Matsuno, T., 1966: Quasi-geostrophic motions in the equatorial area. J. Meteor. Soc. Japan, 44, 25-43, doi:10.2151/ jmsj1965.44.1_25.

McGregor, S., A. Sen Gupta, and M. H. England, 2012: Constraining wind stress products with sea surface height observations and implications for Pacific Ocean sea level trend attribution. J. Climate, 25, 8164-8176, doi:10.1175/ JCLI-D-12-00105.1.

- A. Timmermann, M. F. Stuecker, M. H. England, M. Merrifield, F.-F. Jin, and Y. Chikamoto, 2014: Recent Walker circulation strengthening and Pacific cooling amplified by Atlantic warming. Nat. Climate Change, 4, 888-892, doi:10.1038/nclimate2330.

Muñoz, E., A. Busalacchi, S. Nigam, and A. Ruiz-Barradas, 2008: Winter and summer structure of the Caribbean low-level jet. J. Climate, 21, 1260-1276, doi:10.1175/2007JCLI1855.1.

Parks, T. W., and C. S. Burrus, 1987: Design of linear-phase finite impulse-response. Digital Filter Design, John Wiley \& Sons, 33-110.

Rasmusson, E. M., and T. H. Carpenter, 1982: Variations in tropical sea surface temperature and surface wind fields associated with the Southern Oscillation/El Niño. Mon. Wea. Rev., 110, 354-384, doi:10.1175/1520-0493(1982)110<0354: VITSST $>2.0 . \mathrm{CO} ; 2$.

Rayner, N. A., D. E. Parker, E. B. Horton, C. K. Folland, L. V. Alexander, D. P. Rowell, E. C. Kent, and A. Kaplan, 2003: Global analyses of sea surface temperature, sea ice, and night marine air temperature since the late nineteenth century J. Geophys. Res., 108, 4407, doi:10.1029/2002JD002670.

Rodríguez-Fonseca, B., I. Polo, J. Garcia-Serrano, T. Losada, E. Mohino, C. R. Mechoso, and F. Kucharski, 2009: Are Atlantic Niños enhancing Pacific ENSO events in recent decades? Geophys. Res. Lett., 36, L20705, doi:10.1029/ 2009GL040048.

Romero-Centeno, R., J. Zavala-Hidalgo, A. Gallegos, and J. J. O'Brien, 2003: Isthmus of Tehuantepec wind climatology and ENSO signal. J. Climate, 16, 2628-2639, doi:10.1175/ 1520-0442(2003)016<2628:IOTWCA > 2.0.CO;2.

_ _ _ and G. B. Raga, 2007: Midsummer gap winds and lowlevel circulation over the eastern tropical Pacific. J. Climate, 20, 3768-3784, doi:10.1175/JCLI4220.1.

Saha, S., and Coauthors, 2010: The NCEP Climate Forecast System Reanalysis. Bull. Amer. Meteor. Soc., 91, 1015-1057, doi:10.1175/ 2010BAMS3001.1.

Small, R. J. O., S. P. de Szoeke, and S.-P. Xie, 2007: The Central American midsummer drought: Regional aspects and 
large-scale forcing. J. Climate, 20, 4853-4873, doi:10.1175/ JCLI4261.1.

Steenburgh, W. J., D. M. Schultz, and B. A. Colle, 1998: The structure and evolution of gap outflow over the Gulf of Tehuantepec, Mexico. Mon. Wea. Rev., 126, 2673-2691, doi:10.1175/1520-0493(1998)126<2673:TSAEOG > 2.0.CO;2.

Sun, F., and J.-Y. Yu, 2006: Impacts of Central America gap winds on the SST annual cycle in the eastern Pacific warm pool. Geophys. Res. Lett., 33, L06710, doi:10.1029/ 2005GL024700.

Wallace, J. M., and D. S. Gutzler, 1981: Teleconnections in the geopotential height field during the Northern Hemisphere winter. Mon. Wea. Rev., 109, 784-812, doi:10.1175/ 1520-0493(1981)109<0784:TITGHF > 2.0.CO;2.

Wang, C., 2005: ENSO, Atlantic climate variability, and the Walker and Hadley circulations. The Hadley Circulation: Past, Present, and Future, H. F. Diaz and R. S. Bradley, Eds., Kluwer Academic, 173-202.

2006: An overlooked feature of tropical climate: InterPacific-Atlantic variability. Geophys. Res. Lett., 33, L12702, doi:10.1029/2006GL026324.

_ 2007: Variability of the Caribbean low-level jet and its relations to climate. Climate Dyn., 29, 411-422, doi:10.1007/ s00382-007-0243-z.

, D. B. Enfield, S.-K. Lee, and C. W. Landsea, 2006: Influences of the Atlantic warm pool on Western Hemisphere summer rainfall and Atlantic hurricanes. J. Climate, 19, 3011-3028, doi:10.1175/JCLI3770.1.

, S.-K. Lee, and D. B. Enfield, 2008: Climate response to anomalously large and small Atlantic warm pools during the summer. J. Climate, 21, 2437-2450, doi:10.1175/2007JCLI2029.1.

Xie, S.-P., and Z.-Q. Zhou, 2017: Seasonal modulations of El Niñorelated atmospheric variability: Indo-western Pacific ocean feedback. J. Climate, 30, 3461-3472, doi:10.1175/JCLI-D-16-0713.1.

- , H. Xu, W. S. Kessler, and M. Nonaka, 2005: Air-sea interaction over the eastern Pacific warm pool: Gap winds, thermocline dome, and atmospheric convection. J. Climate, 18, 5-20, doi:10.1175/JCLI-3249.1.

Xu, H., S.-P. Xie, Y. Wang, and R. J. Small, 2005: Effects of Central American mountains on the eastern Pacific winter ITCZ and moisture transport. J. Climate, 18, 3856-3873, doi:10.1175/ JCLI3497.1.

Zamudio, L., H. E. Hurlburt, E. J. Metzger, S. L. Morey, J. J. O'Brien, C. Tilburg, and J. Zavala-Hidalgo, 2006: Interannual variability of Tehuantepec eddies. J. Geophys. Res., 111, C05001, doi:10.1029/2005JC003182.

Zebiak, S. E., 1993: Air-sea interaction in the equatorial Atlantic region. J. Climate, 6, 1567-1586, doi:10.1175/ 1520-0442(1993)006<1567:AIITEA > 2.0.CO;2.

Zhang, W., F.-F. Jin, J.-X. Zhao, and J. Li, 2013: On the bias in simulated ENSO SSTA meridional widths of CMIP3 models. J. Climate, 26, 3173-3186, doi:10.1175/JCLI-D-12-00347.1. 